Carbon dioxide forms the chief constituent of the gaseous mixture where putrid odor abounds. In other cases hydrogen predominates. The contents of the cans show little change. There is no offensive odor. There is absence of bacteria. There are positive indications of the corrosion of the inner metallic surfaces. Sometimes there is a discoloration of the can as if a slight amount of hydrogen sulphide had been formed. The contents of such cans also yield the reactions of the metals. Hydrogen has also been found where the evidences of corrosion were not marked. With the above clues afforded by the inspection of the contents of the can, the gases in the eudiometer may be subjected to the action of proper reagents in such order as to determine at least the main constituents. The reagents may be allowed to enter the stop-cock eudiometer, or the gases be transferred to pipettes as is customary in gas analysis. The recognition of traces of substances whose odor is very marked is difficult ; for some we have no adequate tests.

COLLEGE OF THE CITY OF NEW YORK.

\title{
MECHANICAL ARRANGEMENT OF FAT EXTRACTION APPARATUS.
}

\author{
By G. J. VolckeniNG.
}

Received fuly 77,1897 .

THE apparatus shown in the accompanying drawing has 1 been in use in the Chemical Laboratory of the Brooklyn Health Department for the past eighteen months. It was designed to meet the demand often experienced in food laboratories where large numbers of samples of milk are submitted for analysis. Too often is the chemist given an unoccupied roon of no apparent use for other purposes and is told to build a laboratory. The disadvantage of a small laboratory was experienced. A separate room could not be given up for fat extraction; consequently this work had to be performed in the general and only room in the presence of naked flames. It was, therefore, necessary to produce a piece of apparatus that was compact, free from any chance of explosion, of a capacity sufficient to meet all demands and simple enough to be operated by the laboratory boy. About two feet above the table, on the wall, is 
fastened the waste pipe, which receives the water after it has passed through the condensers. In order to obviate any back pressure the pipe is made larger and carried direct to the sewer, without receiving the discharge from any other fixture. The inlet tubes are built up by using a $T$, an elbow, reducer, and short brass pipe about three inches long. The condensers are supported by clamps to these inlet tubes. The overflows from the condensers are connected by means of rubber tubing to the inlet tubes, which serve a double purpose; that of posts supporting the apparatus, and at the same time acting as outlets for the waste water.

The cold water supply pipe is securely fastened to the wall about six inches below and parallel to the line of waste. As the building was not supplied with a tank, the pressure in the general house supply often dropped below ten pounds. It was found necessary, in order to maintain a constant supply of water at all times, to run a separate line of pipe from the street direct to this table without being connected to any other fixture. There are twenty outlets on the table, each being provided with a separate stop-cock directly under the inlet tube of the waste; consequently each condenser can be operated independently of the others. Thus the number used at any time will depend upon the amount of work on hand.

The ether is heated on gun-metal steam tables, which have been tested up to a pressure of fifty pounds per sqnare inch. In order to give closer contact and thus reduce the time of the operation, small capsules are placed on the table and partly filled with water. The bottoms of the flasks coming in contact with the hot water shortens the time of vaporizing the ether. As a substitute for the capsules a piece of thin felt moistened with water will answer the same purpose. Each steam table will support four sets of extractors. It will be seen by referring to the drawing that each table can be operated independently by means of the separate stop-cocks, and further, if only one table is required the others can be removed with their accompanying apparatus, thus allowing the space to be occupied for other purposes. The steam is generated by an upright tubular boiler heated by gas.

The whole or part of the laboratory table can be used for 
other operations by disconnecting the apparatus. The drawing shows the table as it is used during the winter months, three steam tables being removed and in their place apparatus set up for steam distillation.

\section{THE COMPOSITION OF HUMUS.}

BY HARRY SNYDER

Receiveri Juty 6, 5897

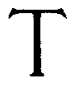

HE organic compounds of the soil to which the term humus is collectively applied, are a group about which but little is actually known. The humus compounds have not been extensively studied because of the difficulty of separating and obtaining them in a pure state. They do not form well-defined crystalline compounds, and they are all about equally soluble in various reagents. In fact, the analyst, when working with the humus compounds, is never sure whether he is working with a single compound or a mixture of several compounds.

The usual method employed in soil analysis for the determination of the humus compounds is the Grandean or some modifcation of that method, which consists of first treating the soil with cold dilute hydrochloric acid to remove the lime, and then, after washing with distilled water, extracting the humus materials with a dilute ammonia solution. The humus extract is evaporated to dryness, dried, weighed, ignited, weighed again, and the loss of weight calculated as humus.

Inasmuch as the organic compounds of the soil may be derived from so many different sources, as any form of decayed animal or vegetable matter, it must necessarily follow that humus is very complex in composition. It seemed best, in this study of the composition of humus, to produce the humus from known materials, rather than to start with humus from unk nown sources. Humus was prepared in the following way: A soil containing only a small known amount of organic material was used. About 200 grams of sugar were mixed with 3,000 grams of soil, placed in a tight box, and allowed to undergo humus formation, out of doors, for one year. Humus was produced in this way from a variety of materials, as cow manure, green clover, meat scraps, wheat flour, saw dust, oat straw, and sugar. 